\title{
ALGUMAS CONSIDERAÇÕES À RESPEITO DO BENEFICIUM COMPETENTIAE
}

\author{
Ignácio Maria Poveda Velasco \\ Professor Doutor do Departamento de Direito Civil da FDUSP
}

Resumo:

As fontes romanas referem-nos diversos casos de devedores os quais, ao serem demandados, eram condenados in id quod facere possunt.

Este tratamento privilegiado denominado, a partir do século XVI, beneficium competentiae livrava o devedor das agruras da execução patrimonial forçada, e afastava o risco de eventual execução sobre sua pessoa.

Demandado por um credor em relação ao qual gozasse do benefício, o devedor seria condenado a pagar na medida de suas possibilidades patrimoniais, ficando, contudo, o réu obrigado ao pagamento do remanescente da dívida.

A condenação limitada, enquanto abrandamento do rigor do direito de crédito, insere-se num contexto de humanização do Direito Romano, atendendo, via de regra, a uma ratio que contempla certos aspectos parentesco, gratidão, afinidade, etc. existentes nas relações entre o devedor beneficiado e seu credor.

Abstract:

The Roman sources refer in the several cases of debtors which, when demanded, were condemned in id quod facere possunt.

This privileged treatment - denominated, starting from the century XVI, beneficium competentiae had liberated the debtor of the acrities of the forced patrimonial execution, and it moved away the risk of eventual execution on its person.

Demanded by a creditor in relation to which enjoyed the benefit, the debtor would be condemned to pay in the measure of its patrimonial possibilities, being, however, the defendant forced to the payment of the remainder of the debt.

The limited condemnation, while softening the rigidity of the creditor's right, interferes in a context of humanization of the Roman Law, assisting, regularly, to a ratio that contemplates certain aspects - relationship, gratitude, likeness, etc. existent in the relationships between the debtor beneficiary and its creditor.

Unitermos: devedor, credor, patrimônio. 
I - Introdução*

O presente trabalho visa efetuar uma revisão crítica do beneficium competentiae ou condemnatio in id quod debitor facere potest, condenação limitada, no âmbito do Direito Romano.

De acordo com as fontes romanas, sobretudo o Digesto, alguns devedores eram condenados, em determinadas circunstâncias, a pagar não a totalidade da dívida mas apenas aquilo que estivesse dentro de suas possibilidades patrimoniais. As consequiências práticas deste favorecimento do devedor eram notáveis. Antes de tudo, ele afastava a possibilidade da execução pessoal (ao menos enquanto foi aplicada em Roma) que o devedor sofreria, caso seu patrimônio não bastasse para saldar seus débitos. E, em qualquer caso, evitava os indesejáveis desdobramentos do processo falimentar, que culminava na bonorum venditio, incluindo a pena de infamia.

O benefício ${ }^{1}$ da condenação limitada pode inserir-se no processo de humanização do velho Ius civile, processo que se inicia sob a égide da filosofia grega - notadamente o Estoicismo, ${ }^{2}$ com sua visão cosmopolita da fraternidade universal e seu apreço pela humanitas $^{3}$ - e prossegue sob o influxo crescente do cristianismo a partir dos primeiros séculos da nossa era. ${ }^{4}$ Analisando a evolução dos casos de concessão deste favor, podemos observar, no terreno das obrigações, um processo paralelo ao ocorrido, no âmbito do Direito Romano, quanto ao tratamento

* Nas citações bibliográficas, a referência a uma obra já anteriormente citada de um autor virá sempre seguida da identificação da nota de rodapé onde ela pela primeira vez apareceu, trazendo suas indicações essenciais. Assim, v.g.: Guarino, La condanna..., cit. (nota 6, I) = obra já anteriormente citada, com seus dados completos, na nota 6 do capítulo $I$.

1. A respeito da utilização do termo beneficium e vocábulos afins (favor, honor, etc.) nos textos, vide infra cap. II, 1.

2. Ver, a propósito, Corrêa, O estoicismo no direito romano, São Paulo, 1950, pp. 7 119. Tese (Livre Docência). Faculdade de Direito, Universidade de São Paulo. Cf., também, Schulz, Storia della giurisprudenza romana, Firenze, Sansoni, 1968, pp. 3592 (particularmente, sobre o período helenístico, pp. 73 e ss., 110 e 119 e ss.; e sobre a filosofia estóica, pp. 120, 129, 157 e 534).

3. Cf. Schulz, Principios del derecho romano, trad. esp. de M. Abellán Velasco, Madrid, Civitas, 1990, pp. 23 - 274 (particularmente sobre humanitas, ver às pp. 103 e ss. e 180; e, especialmente, o capítulo destinado à Humanidad (Cap. X), pp. 211 - 242). Ainda, do mesmo autor, Derecho romano clásico, trad. da ed. inglesa por José Santa Cruz Teigeiro, Barcelona, Bosch, 1960, pp. 1 - 606 (sobre a humanitas romana, parágrafos 180, 182, 184 e ss, 240 e 258).

4. Ver, a respeito, Biondi, Il diritto romano cristiano, 3 v., Milano, Giuffrè, 1952; particularmente no v. 3, cap. XXII, o parágrafo relativo ao favor debitoris, pp. 217 - 260. 
dos direitos reais, especialmente o direito de propriedade, a saber: a progressiva atenuação de seu rigor. ${ }^{5}$

Conforme observam diversos autores, ${ }^{6}$ a condenação limitada não constitui propriamente um instituto unitário, ao menos quanto aos direitos préclássico e clássico. O que as fontes nos apresentam são diversos casos nos quais determinados devedores são beneficiados por uma condenação limitada às suas possibilidades econômicas. Esses casos de favorecimento apresentam, contudo, traços comuns que vão se tornando mais claros conforme avançamos pelo direito pós-clássico, até chegarmos à reforma justinianéia. Esta comprovação, aliada a certa conveniência pedagógica, permite-nos falar, uma ou outra vez, da condenação limitada como se de instituto se tratasse.

Quanto à terminologia, embora o assunto venha a ser examinado oportunamente, adiantamos que o nome beneficium competentiae não se encontra nas fontes, podendo, por isso, ser considerado, tecnicamente, incorreto. Tratando-se, contudo, de expressão consagrada pela doutrina, ${ }^{7}$ fornecendo-nos, além disso, mais uma opção terminológica tendo em vista evitar a excessiva repetição de vocábulos, será ela frequientemente usada neste estudo.

A limitação da condenação ao id quod debitor facere potest tem despertado o interesse dos estudiosos ao longo dos tempos. Já Pothier ${ }^{8}$ a ela dedicou sua atenção. Também Lenel $^{9}$ dela se ocupou. Curiosamente, no fim do século

5. Podemos pensar, a este respeito, na redução do caráter absoluto de que parece revestir-se o primitivo dominium, provocada pelo aparecimento dos direitos reais de vizinhança ou pelas limitações administrativas no tocante às construções, etc. Ver, a propósito, Rainer, Bau und nachbarrechtliche Bestimmungen im klassischen römischen Recht, Graz, Leykam Verlag, 1987; e Simshäuser, Die Sozialbindung des Eigentums im römischen Bauwesen der späteren Kaiserzeit in: Sodalitas IV (1984), pp. $1.793-1.814$.

6. Neste sentido, cf., por exemplo, Guarino, La condanna nei limiti del possibile, 2. ed., Napoli, Jovene, 1978, p. 85.

7. Ver, a este respeito, o índice remissivo da maior parte da bibliografia elencada no final do trabalho.

8. Cf. Pandectae Justinianeae in novum ordinem digestae, cum legibus codicis, et novellis, Paris, Gamery, 1818, 5 v. Tomus Secundus, Lib. XVII Pandectarum, Tit. II Pro socio, articulus III De beneficio quo gaudet socius, ut in hoc judicio non ultra quod facere potest condemnetur, $n^{\circ}$ XLVI a $X L I X$, pp. 140 - 141.

9. Cf. Das Edictum perpetuum (ein Versuch zu seiner Wiederherstellung), $2^{\mathrm{a}}$ reimpr. da 3. ed., Leipzig, 1927. Aalen, Scientia, 1974, p. 298, n. 3. 
passado, encontramos na França um surto de teses a respeito: nada menos que sete trabalhos apurados em nosso levantamento bibliográfico. ${ }^{10}$

No início deste século, Pampaloni, romanista italiano, dedicou-se à revisão crítica do instituto, publicando diversos trabalhos. ${ }^{11}$ Também Zanzucchi a ele se dedicou, publicando em 1918 o trabalho Sul c.d. "beneficium competentiae». ${ }^{12}$ Em 1927 Levet publica em Paris ampla monografia a respeito, Le bénéfice de compétence. ${ }^{13}$ Mais tarde, em 1931, Solazzi aborda o tema no cap. XIII da sua obra L'estinzione della obbligazione. ${ }^{14}$ Mais recentemente Guarino lançou-se à revisão crítica do instituto, publicando entre 1938 e 1947 uma série de estudos ${ }^{15}$ que culminam, anos mais tarde, na sua monografia La condanna nei limiti del possibile. ${ }^{16}$ Entre os primeiros escritos do romanista italiano e sua obra definitiva encontramos um ensaio do polonês Litewski ${ }^{17}$ e um trabalho de Marrone. ${ }^{18}$ Finalmente, o alemão

10. São estes os autores: Casteil, F., Du bénéfice de compétence en droit romain (tese, Paris, 1885, 101 p.); Dobriceanu, A., De l'exception quod facere potest (tese, Paris, 1881, 53 p.); Duhail, E., De l'exception de eo quod facere potest (tese, Paris, 1883, 87 p.); Fière, Z., Du bénéfice de compétence ou exception quod facere potest (tese, Paris, 1881, 75 p.); Gerard, O., De l'exception de eo quod facere potest en droit romain (tese, Paris, 1886, 60 p.); Pipi, A.T., Du bénéfice de compétence (tese, Paris, 1884, 63 p.); Saint Plancat, G., De l'exception quod facere potest (tese, Toulouse, 1893, 112 p.). Apud Caes - Henrion.

11. Cf. Sul "beneficium competentiae» a riguardo dell'estraneo che "donationis causa» promette una dote, e sulla responsabilità del marito per la medesima in AG (Archivio Giuridico "Filippo Serafini»), 56 (1896), pp. 3 18; Sulla teoria del "beneficium competentiae» nel diritto romano in Studi F. Schupfer 1, (1898), reimpr. anast. da ed. 1898 - Roma, G. Bretschneider, 1975, pp. 57 - 69); Sul calcolo della «competentia» nel cosi detto "beneficium competentiae» del diritto romano in SSE (Studi Senesi) 15 (1898), pp. 293 - 300; Il «beneficium competentiae» e il calcolo del suo oggeto in RISG (Rivista italiana per le scienze giuridiche), (1912), 52, pp. 198.

12. in BIDR (Bulletino dell'Istituto di diritto romano «Vittorio Scialoja»), 1918, 29, pp. 61 e ss.

13. Cf. Le bénéfice de compétence, Paris, Recueil Sirey, 1927, pp. 3 - 277.

14. Cf. L'estinzione della obbligazione, Napoli, Jovene, 1931, pp. 190 - 232.

15. Cf. Sul «beneficium competentiae» dei «milites» in RIL (Rendiconti dell'Istituto Lombardo di Scienze e Lettere. Classe Lettere), 1938 - 39, 72 - 2, pp. 355 - 401; Sul «beneficium competentiae» dell" «extraneus promissor dotis» in Festschr. Koschaker, 2 (1939), pp. 49 79; Il "beneficium competentiae» del "promissor dotis» in RISG (Rivista italiana per le scienze giuridiche), 1939, 14, pp. 153 e ss.; Studi sulla «taxatio in id quod facere potest» in SHDI (Studia et documenta historiae et iuris), 1941, 7, pp. 5 34; "Nihil facere posse» in Scritti Ferrini Univ. Cattolica Milano, 1 (1947), pp. 299 - 304.

16. Cf. La condanna..., cit. (nota 6,1$)$.

17. Cf. Das «beneficium competentiae» im römischen Recht in Studi Volterra, 4 (1971), pp. 469 572.

18. Cf. Note di diritto romano sul c.d. «beneficium competentiae» in AUPA (Annali del Seminario Giuridico dell'Università di Palermo), 36 (1976), pp. 5 - 47. 
Gildemeister publicou em 1986 trabalho intitulado Das «beneficium competentiae» im klassischen römischen Recht. ${ }^{19}$

Dentre esses estudos, os de Levet e Guarino têm-nos especialmente servido de orientação para nosso aprofundamento: o do romanista francês por ser a primeira análise ampla sobre o assunto, e o do segundo, por constituir, conforme nos parece, o mais importante trabalho de revisão do instituto, dentre os mais recentes. Os trabalhos restantes foram utilizados para complementação e aprofundamento do nosso, num ou noutro ponto.

Finalmente, duas palavras apenas relativas ao resultado final do trabalho. $\mathrm{O}$ tema que escolhemos nos parece constituir notável exemplo de como os estudos romanísticos podem sempre contribuir grandemente para estímulo dos juristas modernos. A condenação do devedor romano a pagar, em determinados casos, apenas até onde pudesse (in id quod facere potest), e, particularmente a introdução da deductio ne egeat, da qual se falará no fim do trabalho, além de demonstrar o sentido profundamente humano e anti-individualista do ordenamento jurídico de Roma, superior, por vezes, ao do direito moderno ${ }^{20}$ pode ser vista como base analógica de inúmeros institutos do nosso direito, tais como a impenhorabilidade de bens e utensílios de trabalho, a constituição do bem de familia ${ }^{21}$ a proibição, constante do Código Civil, de doações que reduzam o doador à indigência ${ }^{22} \ldots \mathrm{O}$ mesmo espírito de eqüidade inspira por certo, desde a Idade Média, a cláusula «rebus sic stantibus» e os arts. $1.4671 .469,1.664$ e 1.815 do Código Civil italiano sobre "onerosità excessiva" Pode-se pensar, finalmente, em certa orientação na política de renegociação da dívida externa dos países do terceiro mundo, reconhecendo a existência do débito, mas sustentando que a dívida não pode ser paga à custa da miséria do povo.

19. Das beneficium competentiae im klassischen römischen Recht, Göttingen, Otto Schwartz \& Co., 1986, pp. 1 89. Ver recensão crítica de Marrone in IURA (Rivista internazionale di diritto romano e antico), 37 (1986), pp. 137147.

20. Cf., nesse sentido, De Martino, Individualismo e diritto romano privato in Annuario di Diritto Comparato e di Studi Legislativi, v. 16, 1941, p. 49 [= in Diritto e società nell'antica Roma, Roma, Editori Riuniti, 1979, p. 308].

21. Nesse sentido, ver Azevedo, Da penhora, São Paulo, co-edição Fieo e Resenha Tributária, 1994, pp. 137 e ss. Sobre a impenhorabilidade de bens, ver ítens II e ss. do art. 649 do Código de Processo Civil brasileiro em vigor. A respeito do bem de familia ver Lei n. 8.009/90, a qual, ao introduzir a instituição legal do mesmo, estende o alcance do art. 70 do Código Civil brasileiro em vigor, ampliando a proteção à família e, também, ao cabeça de família devedor.

22. Cf. Código Civil brasileiro, art.1.175. 


\title{
II. Beneficium Competentiae
}

\author{
II. 1 Conceito. Terminologia
}

As fontes romanas apresentam-nos diversos casos de devedores obrigados a pagar não a totalidade da dívida mas apenas uma parte, mais precisamente aquilo que puderem fazer: id quod facere possunt. ${ }^{1}$ Esta prática representa exceção à regra pela qual o devedor é compelido a oferecer por inteiro a prestação. $^{2}$

Em condições normais, o devedor insolvente ver-se-ía sujeito aos rigores da execução patrimonial forçada ${ }^{3}$ e, não sendo os seus bens suficientes para a satisfação dos credores, tornar-se-ía objeto de execução pessoal. ${ }^{4} \mathrm{~A}$ vantagem

1. Assim, por exemplo, Ulp. 31 ed., D. 17, 2, 63 pr.; Paul. 6 Plaut., D. 42, 1, 19, 1; Ulp. 36 Sab., D. 24, 3, 12. Cf., nesse sentido, entre outros, Volterra, Istituzioni di diritto romano, Roma, Ricerche, 1961, p. 605; Burdese, Manuale di diritto privato romano, Torino, U. T. E. T., 1964, p. 694; Iglesias, Derecho romano. Instituciones de derecho privado, 2.ed., Barcelona, Ariel, 1953, v. 2, p. 171; Kaser, Derecho privado romano, trad. esp. da 5.ed. alemã por José Santa Cruz Teijeiro, 2.ed., Madrid, Reus, 1982, p. 151; Cuq, Les institutions juridiques des romains, Paris, Plon-Nourrait et Cie., 1902, v. 2, p. 741; e Buckland, A manual of roman private law, 2.ed., Cambridge, University Press, 1953, p. 371.

2. Vide Ulp. 32 ed., D. 19, 1, 13, 8 e Mod. 3 resp., D. 22, 1, 41, 1. De acordo com Solazzi, L'estinzione..., cit. (nota 14, I), p. 179, dois são os institutos que constituem exceção a esta regra: a concordata e o chamado beneficium competentiae. Do primeiro, também designado com o nome de pactum ut minus solvatur, cuidam Ulp. 4 ed., D. 2, 14, 7, 17 19; Pap. 10 resp., D. 2, 14, 8; Paul. 62 ed., D. 2, 14, 9; Ulp. 4 ed., D. 2, 14, 10 pr. Na opinião de alguns, trata-se de precedente da moderna concordata. Nesse sentido ver Moreira Alves, Direito romano, v.2, 4.ed., Rio de Janeiro, Forense, 1986, pp. 42 e 47 e, recentemente, Marchi, Do «pactum ut minus solvatur» - precedente romano da concordata moderna, São Paulo, 1995. O beneficium competentiae, contudo, não constitui exceção ao princípio, lembrado por Gai. 3, 168, de que a obrigação se extingue pelo pagamento do débito pois, como se verá mais adiante, subsiste uma obrigação pelo restante da dívida, pela parte não-satisfeita pelo devedor.

\section{A respeito deste assunto, ver infra cap. III, 2.}

4. A execução pessoal existente no Direito Romano reflete a preocupação daquele ordenamento jurídico com a tutela do credor e de seu patrimônio. De acordo com Wenger, Compendio de derecho procesal civil romano, 2.ed. in Jörs - Kunkel, Derecho privado romano, trad. esp. da 2.ed. alemã por L. Pietro Castro, Barcelona, Labor, 1937, p. 533, os traços do primitivo direito de execução romano não deixam entrever qualquer concessão a sentimentos sociais. Mais tarde, porém, este rigor sofrerá sucessivas atenuações, sem contudo desaparecer por completo. A Lei das XII Tábuas $(3,1 \quad 6)$ regulamentou o processo de execução pessoal com riqueza de pormenores. Em face dela, o credor podia obter do magistrado a adjudicação a seu favor do devedor insolvente, submetendo-o a cárcere privado. Após apresentá-lo em público por três dias consecutivos, a fim de ver se alguém se oferecia para resgatar o insolvente, o credor podia matá-lo ou vendê-lo fora de Roma como escravo. Contudo, o bom senso, aliado ao sentido pragmático do credor romano, leva-nos a pensar que ele preferisse a segunda possibilidade, reavendo, assim, seu dinheiro. A Lei Poetelia Papiria, de 326 a.C., embora reduzindo os rigores da execução pessoal, não chegou, no entanto, a suprimi-la. A partir dessa data, o 
prática do benefício da condenação limitada era, precisamente, livrar o devedor das agruras da execução patrimonial que incluía a nota infamante, ${ }^{5}$ e da eventual execução sobre sua pessoa.

Este abrandamento do rigor do direito de crédito insere-se, como referido acima, num contexto de humanização do Direito Romano, que passa a levar em consideração aspectos (de parentesco, gratidão, afinidade, matrimônio, sociedade, patronato, etc.) por ventura existentes na relação credor-devedor. ${ }^{6}$

No direito pós-clássico e, principalmente, na compilação justinianéia, o beneficium competentiae mudou seu perfil. Tendo a execução pessoal caído em desuso neste período, sua principal conseqüência prática passou a ser a exclusão de alguns bens da execução patrimonial, com a finalidade de garantir a subsistência do devedor e evitar que ficasse reduzido à indigência. É a deductio ne egeat da qual trataremos com mais detalhe infra, estendida por força da prescrição contida em Paul. 6 Plaut, D. 50, 17, 173 pr., a todos os devedores que gozavam da condenação limitada.

credor foi obrigado a tentar primeiramente a execução dos bens do devedor, e só no caso em que esta não bastasse para a plena satisfação de seu crédito é que poderia proceder à execução na pessoa do réu. Mesmo assim, este passaria a sofrer, por força da referida lei, apenas uma escravidão mitigada e temporária, destinada a satisfazer com seu trabalho forçado, o crédito do exeqüente, ficando excluídos a prisão, o acorrentamento, a morte e a venda do devedor. Com semelhante perfil, a execução pessoal perdura no Direito Romano por muito tempo, avançando por todo o período clássico e mesmo além. Alguns autores, assim D'ORS, Derecho privado romano, 5.ed., Pamplona, Eunsa, 1983, pp. 161-2, põem em dúvida, por razões de ordem prática, a sua efetiva aplicação. Contudo, a doutrina é unânime em reconhecê-la. Resquícios da responsabilidade pessoal do devedor sobrevivem até nossos dias no instituto da prisão civil, restrita modernamente aos casos do depositário infiel e do alimentante inadimplente. Ver, a respeito, Álvaro Villaça Azevedo, Prisão civil por dívida, São Paulo, RT, 1993, pp. 17 - 27.

5. O réu condenado na actio iudicati e submetido à bonorum venditio, sofria também a infamia . De acordo com Arangio-Ruiz, La società in diritto romano, Napoli, Jovene, 1982, pp. 185-6, o infame incluía-se naquela categoria de pessoas (ignominiosae) que não podiam postulare pro aliis, ou seja, representar terceiros em juízo, nem ser representados por outros. Sofria, além disso, outras limitações instituídas por lei (concretamente, a relativa à validade de seu testemunho) ou pela prática dos tribunais (como, por exemplo, a vantagem que o filho deserdado pelo pai teria na querela inofficiosi testamenti se o estranho preferido pelo genitor fosse infamia notatus).

6. Por não constituir propriamente instituto unitário (cf. introdução, supra), não se pode pensar numa ratio única que servisse para justificar a concessão do benefício a determinados devedores e não a outros. Contudo, na maioria dos casos, observa-se a existência dessas circunstâncias qualificativas da relação credor-devedor, traduzíveis em motivos de gratidão, respeito, consideração, etc., e que tornam razoável o abrandamento do rigor iuris. Cf., nesse sentido, Perozzi, Istituzioni di diritto romano, v. 2. Firenze, G. Barbèra Editore, 1908, p. 325. Guarino, La condanna..., cit. (nota 6, I), p. 23, julga poder entrever, nas fontes disponíveis, alguma orientação ou motivação comum aos diversos casos de concessão do benefício. 
Ao referir-se a nosso instituto as fontes utilizam por vezes os termos beneficium ${ }^{7}$ e honor. ${ }^{8}$ É natural que assim seja, considerando-se que a providência cria inegavelmente vantagem para o devedor. ${ }^{9}$

O emprego desses termos tem levado alguns autores ${ }^{10}$ a ver na condenação limitada manifestação do ius singulare. Segundo Bonfante, ${ }^{11}$ os direitos singulares mais importantes são aqueles que estabelecem disposições de favor para oportunamente abrandar, em determinadas circunstâncias, a aplicação rigorosa dos princípios gerais. Essas exceções constituem, em sua opinião, vasta categoria que recebe o nome de beneficia legis, dentre os que destaca o beneficium inventarii, o beneficium abstinendi e o beneficium competentiae. ${ }^{12}$

Apesar de o benefício ser indiretamente apresentado por Paulo, de iur. sing., D. 24, 3, 54, como se de ius singulare se tratasse, Guarino ${ }^{13}$ discorda dessa interpretação, oferecendo diversas razões. Em primeiro lugar, diz ele, a categoria do ius singulare não é clássica e sim criação pós-clássica. Em segundo lugar, o referido Liber singularis de iure singulari atribuído a Paulo, é apócrifo. Mas, principalmente, porque é certo que a condemnatio in id quod facere potest difundiu-se, em época clássica, por analogia, fora dos casos previstos pelo edito, interpretação esta nãoadmissível para um instituto do ius singulare. ${ }^{14}$

7. Cf. Ulp. 31 ed., D. 17, 2, 63, 1; Paul. 7 Sab., D. 24, 3, 13; Paul. 14 quaest., D. 42, 1, 41, 2.

8. Cf. Paul. 7 Sab., D. 24, 3, 15, 2 e 17 pr.

9. Outras denominações, de caráter processual (condemnatio, taxatio, praescriptio, etc.), serão examinadas adiante ao tratar da natureza processual do benefício.

10. Assim, entre outros, Arias-Ramos, Derecho romano, 5.ed., Madrid, Ed. Rev. de Derecho Privado, 1951, v. 1, p. 34

11. Cf. Istituzioni di diritto romano, 10.ed., Torino, Giappichelli, 1946, p. 16. Às pp. 420 e ss. volta a referir-se ao beneficium competentiae como instituto de ius singulare.

12. Do mesmo teor é a definição atribuída a Paulo, de iur. sing., D. 1, 3, 16: Ius singulare est, quod contra tenorem rationis propter aliquam utilitatem auctoritate constituentium introductum est. [Direito singular é o introduzido pela autoridade dos que o constituem como exceção ao direito comum, por causa de alguma utilidade].

13. Cf. La condanna..., cit. (nota 6, I), p. 19. Vide, também, do mesmo autor, Studi sulla «taxatio»..., cit. (nota 15, I), pp. 20 e ss.

14. Nesse sentido, Paul. 54 ed., D. 50, 17, 141 pr.; Iul. 27 dig., D. 1, 3, 15. Cf. Garcia-Garrido, Derecho privado romano, 4.ed., Madrid, Dykinson, 1989, p. 138. Diferentemente, D'ORS, Derecho privado..., cit. (nota 4, I), p. 60, citando, como exemplo, a extensão em favor do Erário do direito singular do Fisco (Modest. 6 excus., D. 19, 2, 49, 1). Seja como for, para Kaser, Derecho privado..., cit. (nota $1, \mathrm{~m}$ ), p. 32, a contraposição entre ius commune e ius singulare (entendido este como 
A condenação limitada era, na verdade, beneficium no sentido estrito da palavra: disposição estabelecida a favor de determinadas situações jurídicas para atenuar a aplicação de um princípio do ius commune. Trata-se de direito, o qual podia solicitar qualquer pessoa que se encontrasse nas circunstâncias objetivas previstas, mas cuja concessão somente se dava quando previamente solicitada ao magistrado ou ao imperador. ${ }^{15}$

A expressão beneficium competentiae, contudo, é estranha às fontes. Encontramo-la na literatura romanística, pela primeira vez, no séc. XVI, vulgarizando-se a partir do século seguinte. ${ }^{16}$ No latim medieval, o termo competentia designava aquele mínimo de bens imprescindíveis para se enfrentar as necessidades elementares da existência ou, ainda, "suficiência de meios para viver" ${ }^{17}$ Esse conceito identifica-se com a deductio ne egeat que, no Direito Justinianeu, passa a ser o elemento preponderante da condenação limitada, em virtude da qual excluíam-se da execução do devedor beneficiado alguns bens, para se evitar que ele ficasse reduzido à indigência. De acordo com Arangio-Ruiz, ${ }^{18}$ esta aproximação entre a condenação limitada e a deductio ne egeat, transformando aquela num simples benefício alimentar, provavelmente acabou favorecendo a consagração da expressão beneficium competentiae. ${ }^{19}$

exceção ao primeiro) não tem grande importância: ambos são conceitos teóricos, desenvolvidos pela doutrina do Direito comum, cuja paternidade não pode ser atribuída aos juristas clássicos.

15. Paul., de adsig. libert., D. 50, 17, 69. Cf. Garcia-Garrido, Derecho privado.., cit. (nota 14, II), p. 139. Vide, também, Iglesias, Derecho romano..., cit. (nota 1, M), v.1, p. 26.

16. Cf. Guarino, La condanna..., cit. (nota 6, I), p. 19. Vide, também, minuciosa exposição sobre o assunto em Levet, Le bénéfice..., cit. (nota 13, I), pp. XV e ss.

17. Cf. Schulz, Derecho romano..., cit. (nota 3, D), p. 440. Daí também, de acordo com o autor, a palavra inglesa competence ou competency.

18. Cf. La società..., cit. (nota 5, I), p. 183, nota 1 .

19. Guarino, La condanna..., cit. (nota 6, I), p. 22, usa a expressão beneficium condemnationis, ao que parece como sinônimo de beneficium competentiae. À p. 25 da mesma obra, volta a empregá-la em contraposição à expressão beneficium exsecutionis com a qual, segundo ele, alguns pandectistas designavam a deductio ne egeat. Contudo, anteriormente, ele recusara a utilização dessa nomenclatura: cf. Guarino, Studi sulla «taxatio»..., cit. (nota 15, I), p.8. 


\section{2 Características}

O beneficium competentiae apresentava algumas características que vale a pena ressaltar. A primeira é seu caráter pessoal que o tornava intransferível (aos fiadores, por exemplo) e intransmissível causa mortis. ${ }^{20}$ Além disso, era ele irrenunciável. $^{21}$

Por outro lado, já vimos como o benefício reduzia a condenação do réu, que ficava obrigado a pagar apenas na medida de suas possibilidades patrimoniais. Contudo, a condemnatio limitada não reduzia o valor da dívida, razão pela qual o réu ficava obrigado a pagar o restante assim que sua situação econômica melhorasse. ${ }^{22}$ Com tal finalidade, o juiz, no processo formular, antes de condenar o réu, obrigava-o a prometer ao credor, através de contrato verbal, que pagaria o remanescente caso viesse a se restabelecer economicamente. Essa promessa tinha por objeto o id quod rei iudicatae tempore facere non potuit e assumia a forma de uma cautio pela qual o devedor prometia restituere quod minus persolvit, si ad meliorem fortunam pervenerit. ${ }^{23}$ A obrigação assim surgida não era meramente natural mas civil, e garantia o credor contra a eficácia extintiva da litis contestatio. ${ }^{24}$

20. Cf. Paul. 60 ed., D. 42, 1, 25 ; Paul. 3 ad Plaut., D. 44, 1, 7 pr. Nesse sentido, Volterra, Istituzioni..., cit. (nota 1, II), p. 702; D'ORS, Derecho privado..., cit. (nota 4, II), p. 120; e Cuq, Les institutions..., cit. (nota 1, II), p. 741, nota 1.

21. Cf. Ulp. 36 Sab., D. 24, 3, 14, 1. Para Perozzi, Istituzioni..., cit. (nota 6, II), v. 2, p. 325, essa é a orientação do Direito Justinianeu. D'ORS, Derecho privado..., cit. (nota 4, II), p. 120, admitindo que o texto dos comentários de Ulpiano a Sabino é interpolado entende, contudo, que a alteração justinianéia restringe-se ao período final do fragmento, que trata da motivação apresentada para a rejeição da renúncia, mas não atinge a orientação em si. Para ele, a razão da proibição da renúncia não seria a de ordem moral estabelecida pelos compiladores (a de que o pacto de renúncia feriria o respeito tradicionalmente devido ao marido), e sim o fato do acordo agravar a situação do beneficiário, o que era inadmissível.

22. Cf., entre muitos outros, Bonfante, Istituzioni..., cit. (nota 11, I), p. 440 e ss.; e Moreira Alves, Direito romano..., cit. (nota 2, II), v. 2, p. 42, nota 765.

23. Cf. Levet, Le bénéfice..., cit. (nota 13, I), p.178. Ver, também, Solazzi, L'estinzione..., cit. (nota 14, I), p. 198.

24. Cf. Ulp. 31 ed., D. 17, 2, 63, 4 e lust., C. 5, 13, 1, 7 (de 530 d.C.). Ver, nesse sentido, Girard, Manuel élémentaire de droit romain, 8.ed., Paris, Arthur Rousseau, 1929, p. 683, nota 5 e p. 1.098, nota 1; cf., também, Cuq, Les institutions..., cit. (nota 1, In), p. 741. Alguns autores, como Pampaloni, Il «beneficium competentiae» e il calcolo..., cit. (nota 11, I), pp. 198 e ss., consideram que a obrigação de prestar uma cautio era imposta apenas ao sócio, enquanto os demais beneficiários da condenação limitada viam-se livres do quod debitor facere non potuit como decorrência do efeito extintivo da litis contestatio. Contudo, de acordo com Levet, Le bénéfice..., cit. (nota 13, I), p. 180, a grande maioria da doutrina refuta essa opinião. Cf., nesse sentido também, Zanzucchi, Sul c. d. «beneficium competentiae»..., cit. (nota 12, 1), p. 80. 
O benefício, além de pessoal, apresentava certa "relatividade". ou seja, era exercido pelo devedor só contra determinados credores. ${ }^{25}$

Finalmente, ele não se aplicava às ações penais, ${ }^{26}$ nem às ações civis quando, nestas últimas, ficasse provado o dolo por parte do devedor. ${ }^{27}$

\section{3 Natureza Processual}

$\mathrm{Na}$ expressão de Guarino, ${ }^{28}$ a condemnatio in id quod reus facere potest é "modalidade" do processo formular de composição de litígios, cujas primeiras manifestações remontam ao séc. II a.C.

$\mathrm{Na}$ perspectiva do processo civil romano, o beneficium competentiae nasce no âmbito do processo per formulas, com uma natureza cujo perfil, não muito preciso, merece estudo mais atento. Além disso, continua sendo concedido também na extraordinaria cognitio a qual, concorrendo com o processo formular desde o séc. II d.C., impera sozinha no período pós-clássico e justinianeu do Direito Romano.

As fontes nos falam de uma 'condemnatio' in id quod debitor (ou reus) facere potest, ${ }^{29}$ ou quatenus facultates (debitoris) patiuntur, ou non ultra facultates (debitoris). ${ }^{30}$ Como observa Guarino, "nestas expressões, nem sempre o termo 'condemnatio' indica com certeza a condemnatio como cláusula do iudicium (aquela que convida o juiz a condenar si paret, ou, si non paret, a absolver), mas por vezes significa (ou parece significar) a sentença de efetiva condenação que o juiz profere,

25. Assim, o sócio goza do benefício contra os demais sócios, os parentes e os patroni contra os filhos e o liberto, o bonorum cessor contra seus credores, etc. A única exceção é a do miles que goza do benefício erga omnes.

26. Cf., nesse sentido, Buckland, A manual of roman..., cit. (nota 1, M), p. 371.

27. Cf., entre outros, Cuq, Les institutions..., cit. (nota 1, II), p. 741, nota 4. De acordo com o autor, a regra «quodve dolo malo fecerint quo minus possint» (Ulp. 31 ed., D. 17, 2, 63 pr. e 7), introduzida primeiro em matéria de sociedade, generalizou-se.

28. Cf. La condanna.., cit. (nota 6, I), p. 8

29. Cf. Ulp. 31 ed., D. 17, 2, 63 pr., 1 e 7; Ulp. 36 Sab., D. 24, 3, 12 e 14; Paul. 7 Sab., D. 24, 3, 15; Pomp. 16 Sab., D. 24, 3, 18; Ulp. 63 ed., D. 42, 1, 16; Ulp. 10 ed., D. 42, 1, 17; Ulp. 66 ed., D. 42, 1, 18; Paul. 6 Plaut., D. 42, 1, 19; Mod. 2 diff., D. 42, 1, 20; Paul. 6 Plaut., D. 42, 1, 21; Pomp. 21 ad Q. Muc., D. 42, 1, 22; Paul. 6 Plaut., D. 42, 1, 23; Pomp. 4 Plaut., D. 42, 1, 24; Paul. 60 ed., D. 42, 1, 25; Paul. 6 Plaut., D. 50, 17, 173 pr., etc.

30. Cf. Ulp. 36 Sab., D. 2, 14, 49; Pomp. 7 var. lect., D. 42, 1, 30; Inst. 4, 6, 37. 
seja com base em iudicium formular, seja, eventualmente, no âmbito da cognitio extra ordinem" 31

No processo formular, a condenação do réu reduzida sempre a uma soma em dinheiro -, podia ser certa ou incerta. ${ }^{32}$ Incerta quando o montante da condenação não fosse exatamente fixado pelo autor na intentio, mas precisasse ser determinado pelo juiz depois de examinadas certas circunstâncias do caso. $\mathrm{Na}$ hipótese, a avaliação ficava sujeita não ao arbítrio do juiz, mas a algum critério estabelecido pelo pretor, e ao qual aquele era obrigado a ater-se. ${ }^{33}$

Visando evitar condenação excessiva, era freqüente o magistrado judiciário, geralmente solicitado pelo réu, inserir no iudicium uma cláusula limitativa denominada taxatio, termo este que, em rigor, as fontes em nenhum momento empregam. Na verdade, como o próprio Gaio esclarece, ${ }^{34}$ trata-se de expressão nãotécnica utilizada para significar o estabelecimento de um limite ao valor da condenação. $\mathrm{Na}$ exposição gaiana essa limitação constituía um máximo, expresso pelo termo dumtaxat, que o juiz não podia ultrapassar. ${ }^{35}$

31. Cf. La condanna..., cit. (nota 6, I), p. 16

32. Cf., sobre isto, Gai. 4, 39 e ss., que oferece apanhado, embora incompleto, do processo no período clássico.

33. Dentre os vários critérios que as fontes nos apresentam, o mais amplo exprimia-se pelas palavras «quantum iudici aequum (et bonum) videbitur, tantae pecuniae condemnato»; nesse caso, o juiz era convidado a seguir a estimativa corrente no ambiente social, segundo o conceito do aequum et bonum. Contudo, o critério mais comum exprimia-se nas palavras «quanta ea res est (ou erit, ou fuit) tantam pecuniam condemnato», que levava em consideração o valor objetivo, de mercado podemos dizer, da coisa litigiosa no momento da litis contestatio ou da prolação da sentença, conforme o caso. Um pouco mais amplas eram as palavras «quanti actoris interest (ou intererit, ou interfuit), tantam pecuniam condemnato», que convidavam o juiz a considerar, além de seu valor objetivo, também o quid o mais representado pelo interesse do autor em obter a prestação mesma. Ver, a este respeito, Tafaro, La interpretatio ai verba 'quanti ea res est' nella giurisprudenza romana. L'analise di Ulpiano, Jovene, 1980, pp.5-218. Cf., também, Guarino, La condanna..., cit. (nota 6, I), pp. 13-14.

34. Gai. 4, 51: est enim una cum aliqua praefinitione, quae vulgo dicitur cum taxatione.... Além disso, Gaio não menciona a "taxatio in id quod reus facere potest». De acordo com Guarino, La condanna..., cit. (nota 6, I), p. 15, a explicação deste silêncio das Institutas não é o esquecimento de seu autor mas, sim, o fato do conceito de taxatio apresentado por Gaio -limitado ao âmbito da condemnatio incerta-, ser muito restrito e rígido para alcançar a taxatio in id quod reus facere potest, já que esta, freqüentemente, figurava em ações que visavam obter uma condemnatio certa. Guarino, porém, declara ignorar qual seria nesses casos a redação do iudicium. Ver, também, Talamanca, Istituzioni di diritto romano, Milano, Giuffrè, 1990, p. 312, para quem a condemnatio, tanto certa quanto incerta, podia ser limitada por uma taxatio.

35. Cf. Gai. 4, 51 52. No caso de máximo hipotético de dez mil sestércios, a limitação apresentaria a seguinte redação: «iudex $N^{m} N^{m} A^{o} A^{o}$ dumtaxat sestertium $X$ milia condemna: si non paret, absolve». 
Muitos autores interpretam a condenação limitada, em termos processuais, como uma taxatio, ${ }^{36}$ cujo teor seria «dumtaxat quod $N^{s} N^{s}$ facere potest» ou "dumtaxat de eo quod $N^{S} N^{s}$ facere potest». ${ }^{37} \mathrm{Em}$ quanto cláusula da fórmula, a taxatio era inserida pelo pretor na condemnatio, obrigando o juiz a condenar o réu apenas naquilo que ele pudesse fazer, ou seja, no limite de seus recursos patrimoniais.

Há quem sustente que, em certos casos, os efeitos do benefício fossem alcançados através não de taxatio mas de uma praescriptio pro actore inerente à intentio da fórmula. ${ }^{38}$ É o que parecem sugerir alguns textos nos quais se lê que o réu é chamado a juízo (convenitur) pelo autor in id quod facere potest, e não que é condenado (codemnatur) in id quod facere potest. ${ }^{39}$ Nesse caso, a condenação seria limitada mas na medida em que já o pedido do autor era limitado ao id quod reus facere potest. ${ }^{40}$

O interesse do autor em limitar ele próprio a demanda ao id quod reus facere potest seria evitar o efeito extintivo da litis contestatio. Com efeito, desde o momento em que o réu aceitava do autor a fórmula redigida pelo magistrado, o direito pleiteado consumava-se: a litis contestatio o extinguia, tanto ipso iure quanto exceptionis ope. A litis contestatio produzia um efeito novatório pelo qual o direito original desaparecia, surgindo em seu lugar um outro direito, de natureza processual, cujo objeto era a condenação, se houvesse, determinada pelo juiz particular.

De acordo com Levet, ${ }^{41}$ o credor, a quem se lhe opusesse o benefício, poderia ou reconhecer a relação que o unia ao devedor, ou negar os títulos deste à

36. Taxatio 'in id quod (reus) facere potest'. Cf., entre muitos outros, VOCL, Istituzioni di diritto romano, 3.ed., Milano, Giuffrè, 1954, p. 360; Biondi, Istituzioni di diritto romano, Milano, Giuffrè, 1946, p. 310; Arias-Ramos, Derecho romano..., cit. (nota 10, I), v. 1, p. 157; Buckland, A manual of roman..., cit. (nota 1, II), p. 371; Schulz, Derecho romano..., cit. (nota 3, I), p. 440; Talamanca, Istituzioni..., cit. (nota 34, In), p. 312; e Burdese, Manuale..., cit. (nota 1, In), p. 694.

37. Cf. Pugliese, Istituzioni di diritto romano, 2.ed., Torino, Giappichelli, 1990, p. 293, que cita Pomp. 7 var. lect., D. 42, 1, 30; Iglesias, Derecho romano..., cit. (nota 1, I), v. 2, p. 171; e Girard, Manuel élémentaire..., cit. (nota 24, I), p. 1.098, nota 1, que oferece a redação "dumtaxat in id quod facere potest condemna».

38. Assim Levet, Le bénéfice..., cit. (nota 13, I), p. 171 e ss.

39. Ver Ulp. 36 Sab., D. 2, 14, 49; Ulp. 11 ed., D. 4, 4, 3, 4; Pomp. 15 Sab., D. 11, 7, 28; Ulp. 29 ed., D. 14, 5, 4 pr., etc.

40. Cf. Guarino, La condanna..., cit. (nota 6, I), p. 17. Nesse sentido, Ulp. 63 ed., D. 42, 1, 16 e Ulp. 59 ed., D. 42, 3, 4, falariam de réus 'condenados' in id quod facere possunt, por já terem sido demandados limitadamente pelo autor.

41. Cf. Le bénéfice..., cit. (nota 13, I), p. 165. 
condenação limitada. No primeiro caso, não se oporia à inserção na fórmula da cláusula "condemna in id quod facere potest», a qual, como é sabido, modificava tão-somente a condenação. A intentio teria por objeto o crédito inteiro e sobre ele se faria sentir o efeito extintivo da litis contestatio. No segundo caso, o crédito também seria integralmente deduzido em juízo, cabendo ao iudex avaliar a procedência do benefício impetrado pelo réu, além da existência do direito invocado pelo autor.

Em ambos os casos, o exame do iudex abrangeria a demanda toda e a condenação levaria à exoneração parcial do réu, se seu ativo fosse inferior à dívida, ou mesmo completa se seu facere posse fosse nulo. E tudo isto, sempre de acordo com Levet, pela estrita lógica da litis contestatio.

A inserção de uma praescriptio pro actore objetivaria limitar o pedido apenas às possibilidades patrimoniais do devedor, ficando o restante a salvo do efeito extintivo da litis contestatio. ${ }^{42}$ Por esse remanescente, o credor poderia voltar a acionar novamente o devedor, se e quando a situação econômica deste alcançasse substancial melhora.

Contudo, pode-se objetar que tal procedimento seria desnecessário. Com efeito, tendo em vista que, no momento da redação do iudicium, a avaliação do iudex sobre as possibilidades do réu ainda não tinha ocorrido, o montante da nova relação obrigacional que nascia com a litis contestatio seria o valor total da dívida, tal como apresentado na intentio. No momento do julgamento, o iudex, depois de efetuar o cálculo do facere posse, condenaria o réu nesse valor, obrigando-o ao mesmo tempo como referido supra - a se comprometer formalmente pelo que faltasse. $^{43}$

Finalmente, alguns textos referem-se ao nosso instituto como se de exceptio se tratasse. ${ }^{44}$ A maioria dos autores entende ${ }^{45}$ que a exceptio, pelo menos

42. Cf., nesse sentido, também, Guarino, Diritto privato romano, 8.ed., Napoli, Jovene, 1988, p. 212, nota 18.5.3.

43. Talvez, o interesse e a vantagem da inserção da praescriptio com relação àquele contrato formal realizado na presença do iudex fosse subtrair, do efeito extintivo da litis contestatio, a parte da relação jurídica original correspondente ao facere non posse do réu, com o que se conseguiria, por exemplo, a manutenção das garantias inerentes àquele direito.

44. Cf. Ulp. 31 ed., D. 17, 2, 63, 2; Paul. 7 Sab., D. 24, 3, 17, 1; Paul. 14 quaest., D. 42, 1, 41 pr.; Paul. 3 ad Plaut., D. 44, 1, 7 pr.; Tryph. 7 disput., D. 46, 2, 33.

45. Assim, Solazzi, L'estinzione..., cit. (nota 14, D), p.191; Betti, Istituzioni di diritto romano, 2.ed., Padova, Cedam, 1947, p. 299, nota 73; Perozzi, Istituzioni..., cit. (nota 6, I), p. 325; e Girard, Manuel élémentaire..., cit. (nota 24, II), p. 1.098, nota 1. 
em termos da lógica formular, era uma cláusula inserida no iudicium para, se comprovada, obter-se a absolvição in totum do réu, mas não a limitação da condemnatio, não sendo, por esta razão, o meio adequado para dar eficácia ao beneficium competentiae.

Contudo, como salienta Guarino, ${ }^{46}$ daí não se deve concluir peremptoriamente que os textos referidos sejam todos, e por essa única razão da lógica formular, interpolados. Afinal, diz ele, é bem provável que os juristas, particularmente os do fim do período clássico, tenham sido influenciados pelo uso menos rigoroso que do termo exceptio se fazia no processo extra ordinem, e no qual adquiria o sentido amplo de defesa do réu. ${ }^{47}$

São Paulo, março de 1996.

46. Cf. La condanna..., cit. (nota 6, I), pp. 17-8.

47. Guarino, La condanna..., cit. (nota 6, D), p. 18, acrescenta outro argumento: a hipótese de Ulp. $36 \mathrm{Sab}$., D. 2, 14, 49, pela qual, através de pacto, credor e devedor combinassem que o primeiro executaria o segundo nos limites do facere posse (entende-se: fora dos casos em que a condenação limitada já era prevista em lei, no edito, em rescripto imperial, etc.). Nesse caso, se o credor não delimitasse seu pedido na intentio mediante uma praescriptio pro actore, o devedor poderia lhe opor uma exceptio pacti conventi, em virtude da qual, provada a existência do pacto, o réu seria absolvido. Este argumento, porém, não nos parece convincente, pois em tal caso não haveria, em rigor, condenação limitada. 